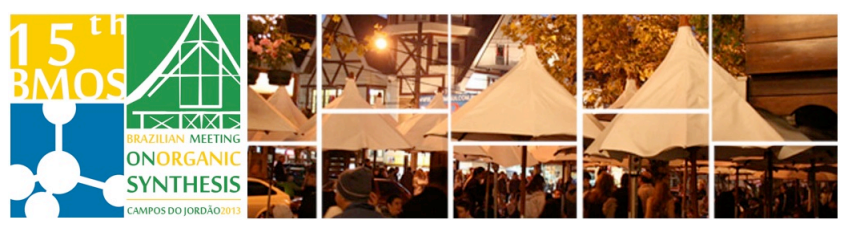

\title{
Targeting Echinococcus granulosus thioredoxin glutathione reductase using a Dynamic Combinatorial approach.
}

\author{
Cecilia Saiz, ${ }^{a}$ Valerie Castillo, ${ }^{a}$ Gustavo Salinas ${ }^{b}$ and S. Graciela Mahler. ${ }^{a}$
}

a. Cátedra de Química Farmacéutica, Facultad de Química, Universidad de la República (UdelaR),

Montevideo, Uruguay. b. Cátedra de Inmunología, Facultad de Química, UdelaR, Montevideo, Uruguay.

*e-mail corresponding author: cecisaiz@gmail.com

Keywords: dynamic combinatorial chemistry, thioredoxin glutathione reductase, sulfur-heterodimers.

\section{INTRODUCTION}

Dynamic Combinatorial Chemistry (DCC) is a synthetic tool that merges chemical synthesis with biological tests in one pot. ${ }^{1}$ The library is under thermodynamic control and introduction of a template could stabilize a compound through library redistribution via reversible bonds. This stabilization could result on an amplification of the best binder.

E. granulosus is a flatworm parasite responsible for cystic hydatid disease. Its thiol redox homeostasis is dependent on an essential single enzyme: thioredoxin glutathione reductase (TGR), which is a key drug target. ${ }^{2}$

\section{RESULTS AND DISCUSSION}

Exploring for new E. granulosus TGR inhibitors through site-specific DCC, we aimed to generate a thiol-disulfide dynamic library using TGR as a template. The library was prepared using TNB (a), commercially available thiols (b-e) and the synthetic thiol (f), ${ }^{3}$ to afford 21 theoretical disulfides. Library distribution was compared before and after enzyme introduction. In presence of the template (TGR), a shift in the equilibrium towards a new stabilized compound (aS-Sf) was observed by HPLC-MS.

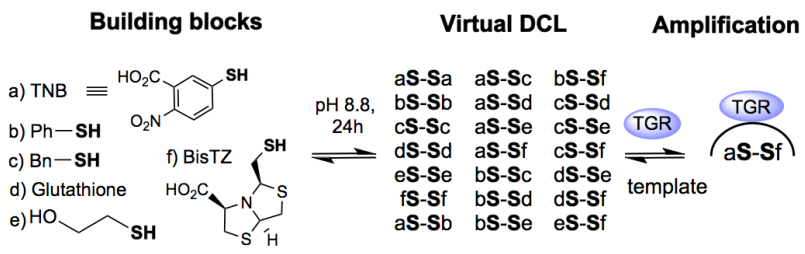

Figure 1. DCL: thiol/disulfide exchange introducing TGR as a template.

Building upon these promising results, we started an independent synthesis of the library-hit aS-Sf and several analogs, see scheme 1.

$A-\mathrm{SH}+\mathrm{B}-\mathrm{SH} \underset{\mathrm{CH}_{2} \mathrm{Cl}_{2}, \mathrm{rt}}{\stackrel{\mathrm{O}_{2}, \text { DMAP }}{\longrightarrow}} A^{-S}{ }^{-} \mathrm{S}^{-B} \quad$ Yields $=35$ to $75 \%$

Scheme 1. General preparation of A-S-S-B heterodimers.
The analogs were prepared by variations in both thiols: the bisthiazolidine moiety (series $A$ ) and the aromatic ring (series $\mathrm{B}$ ):

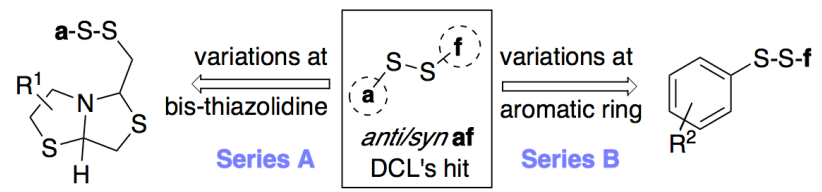

The prepared disulfides were screened for TGR inhibition at $[\mathrm{Inh}]=30 \mu \mathrm{M}$. Compounds with the highest inhibition values were selected for $\mathrm{IC}_{50}$ determination (af, ah and ai); see Figure 2.

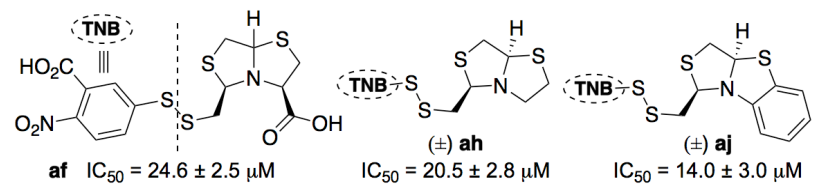

Figure 2. $I C_{50} \pm s d$ values of compounds af, ah, and aj.

A structure activity relationship study was performed and the TNB-tricyclic disulfide (aj) was identified as the best enzyme inhibitor $\left(\mathrm{IC}_{50}=14 \mu \mathrm{M}\right)$.

\section{CONCLUSION}

We have demonstrated the use of a thiol-disulfide DCL using E. granulosus TGR as a template for the first time. The disulfide (af) was identified as a library amplified compound, combining TNB (a) and bisthiazolidine (f). Independent synthesis of (af) and 14 further analogs were carried out for biological evaluation on TGR. Compound (aj) presents the best inhibition value: $I_{50}=14 \mu \mathrm{M}$.

\section{ACKNOWLEDGEMENTS}

ANII, PEDECIBA, CSIC 807, CSIC grupos, FQ.

\section{REFERENCES}

Otto, S.; Furlan, R.; Sanders, J.K.M. Curr. Opin. Chem. Biol. 2002, 6 , 321-327.

${ }^{2}$ Kuntz, A.N.; Davioud-Charvet, E.; Sayed, A.A.; Califf, L.L.; Dessolin, J. et al. PLoS Med 2007 4(6): e206. doi:10.1371/journal.pmed.0040206.

Saiz, C.; Castillo, V. and Mahler, S.G. Synlett 2012, 23, 1090-94 $15^{\text {th }}$ Brazilian Meeting on Organic Synthesis - 15 ${ }^{\text {th }}$ BMOS - November 10-13, 2013 - Campos do Jordão, Brazil 